\title{
ESTRADAS RURAIS E OS IMPACTOS EM BACIAS HIDROGRÁFICAS GERADOS PELA SUA IMPLANTAÇÃO E MANUTENÇÃO
}

\author{
Maikeli Maria Kerniski ${ }^{(a)}$, Marcia Cristina Cunha ${ }^{(b)}$ \\ (a) Programa de Mestrado em Geografia, Universidade Estadual do Centro Oeste do Paraná, Email: \\ mmk.kerniski@hotmail.com. \\ b) Departamento de Geografia, Universidade Estadual do Centro Oeste do Paraná, Email: \\ marcia1cunha@yahoo.com.br.
}

\section{EIXO: BACIAS HIDROGRÁFICAS E RECURSOS HÍDRICOS: ANÁLISE PLANEJAMENTO E GESTÃO}

\begin{abstract}
Resumo
A presença de estradas rurais é fundamental para o desenvolvimento socioeconômico em comunidades rurais. Apesar de sua importância os estudos voltados a explicar os impactos gerados a partir da implantação e manutenção dessas vias, muitas vezes são relegados a segundo plano. Portanto, o objetivo principal deste estudo foi verificar os principais impactos gerados com a implantação e manutenção de estradas rurais na bacia do Rio Guabiroba, localizada no município de Guarapuava PR. Foram utilizados procedimentos metodológicos empíricos, com trabalhos de campo. Por meio dos resultados, observamos que as estradas apresentam problemas como rampas acentuadas de difícil trafegabilidade, encostas instáveis e de difícil manutenção. Conclui-se portanto, que as estradas rurais são de extrema importância para a bacia do Rio Guabiroba, porém necessitam de um planejamento e manutenção adequada, para tornar seu uso viável.
\end{abstract}

Palavras chave: Sistema de drenagem, solo exposto, erosão.

\section{INTRODUÇÃO}

A presença da rede viária em paisagens rurais pode ter mais de um significado com interpretações contrastantes. Essas vias fazem a ligação entre áreas rurais, povoados e vilarejos, e permitem que a população tenha acesso aos serviços básicos disponibilizados nas áreas urbanas, como saúde, educação, lazer e trabalho, servindo também como base para o escoamento da produção agrícola (ODA et al., 2007, CUNHA e THOMAZ et al., 2014). As estradas rurais são compreendidas também como elementos geográficos que exercem forte controle sobre a circulação da água superficial e subsuperficial, sendo importantes na produção e transferência para o rio de sedimentos. (conectividade) (LUCE e WEMPLE, 2001; CHAPPELL, 2010; FAIZ, et al., 2012; WEMPLE, 2013; CUNHA e THOMAZ, 2015).

Segundo Baesso e Gonçalves (2003), as estradas permitem o desenvolvimento das comunidades rurais, e por consequência garantem a melhoria de sua qualidade de vida. Asif et al., (2012) destacam que 
o sistema de transporte que fornece acesso seguro e confiável para empregos, educação, cuidados de saúde

e de bens e serviços é tão importante para as comunidades rurais, quanto é para áreas urbanas. Os sistemas de gerência de vias, que constituem um elenco de atividades coordenadas, relacionadas com planejamento, projeto, construção, manutenção, avaliação e pesquisa, compõem a ferramenta que pode ajudar no planejamento da otimização do uso desses recursos (ODA et al., 2007).

Recentes tentativas têm sido feitas para tornar as estradas mais harmoniosas com o meio ambiente e ao mesmo tempo a integração dos princípios estéticos para torná-las mais atraentes para usuários (CHENG et al., 2015). Contudo, as pesquisas realizadas em estradas rurais são mais comumente direcionadas a explicar os efeitos destas no escoamento superficial e na produção de sedimentos, e pouco se discute sobre os demais impactos que estas geram a partir de sua implantação e manutenção. A bacia do Rio Guabiroba, Guarapuava-PR (área de estudo) tem sido alvo de pesquisas científicas sobre produção de sedimentos em estradas rurais (THOMAZ e MELQUIADES, 2009; CUNHA, 2011; CUNHA, et al., 2013; THOMAZ et al., 2014, CUNHA e THOMAZ, 2015, THOMAZ e PERETTO, 2016, CUNHA, 2016).

Porém, ainda existem poucos trabalhos científicos sobre os impactos que estas estradas causam, e principalmente com sua manutenção, muito embora o Brasil ocupe o quarto lugar com rede viária de estradas sem pavimentação em todo o mundo (FAIZ et al., 2012). Portanto, estudos de impacto ambiental em estradas rurais são necessários, e em condições subtropicais como no Brasil, particularmente em estradas rurais antigas.

O objetivo principal deste estudo foi verificar os principais impactos gerados com a implantação e manutenção de estradas rurais na bacia do Rio Guabiroba, localizada no município de Guarapuava - PR.

\section{MATERIAIS E MÉTODOS}

\section{1 Área de estudo}

Este estudo foi realizado na bacia do Rio Guabiroba no município de Guarapuava, Paraná, Brasil (Figura 1). 


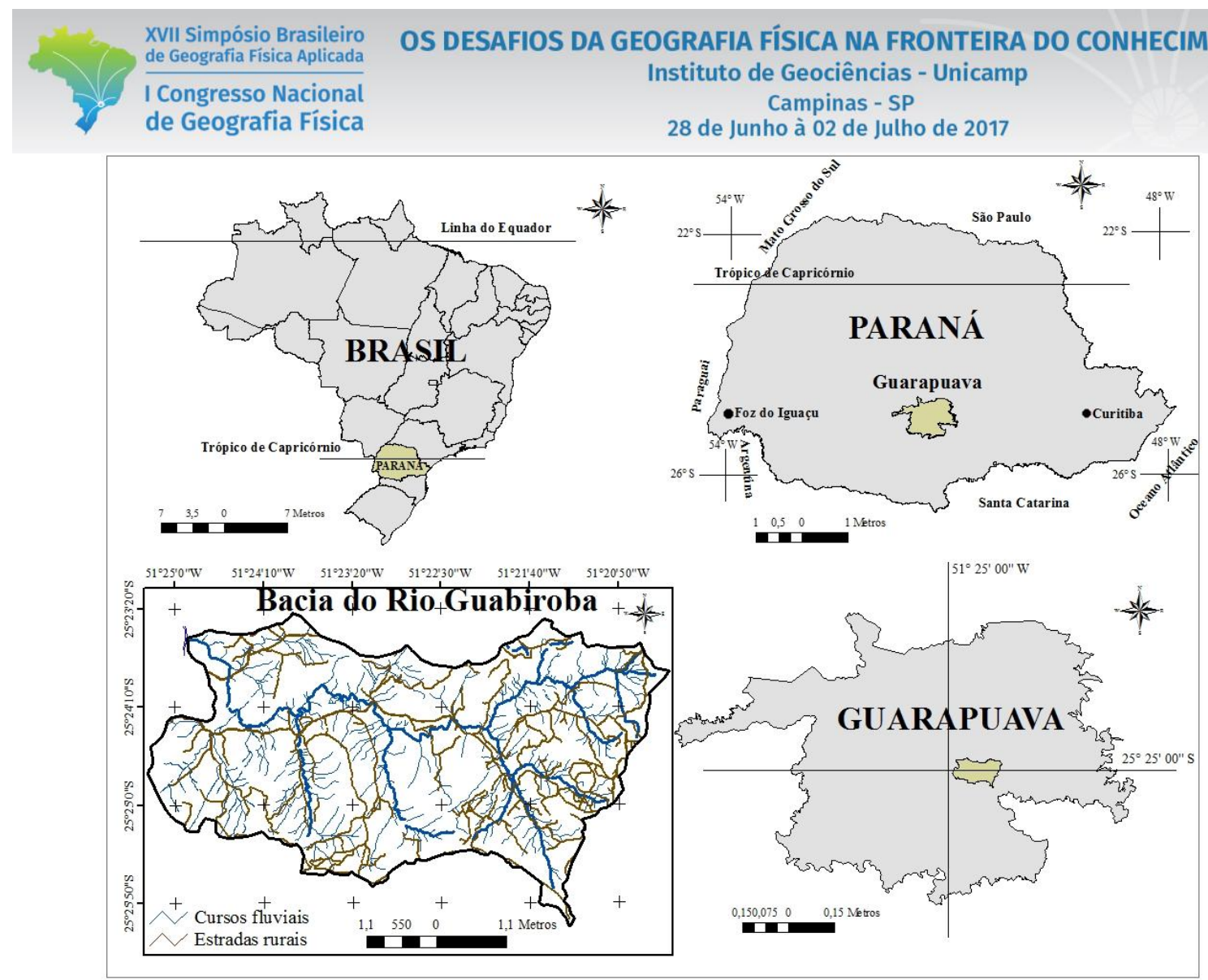

Figura 1- Localização da área de estudo em relação ao município de Guarapuava

Fonte: Elabora pelas autoras (2017).

A bacia possui área de $24 \mathrm{~km}^{2}$ (2,401 ha), a hierarquia fluvial é de $4^{\mathrm{a}}$ ordem em escala de 1:10.000. A litologia predominante da área de estudo é basalto da Formação São Bento (Mineropar, 2001). Existem quatro tipos de solo como cobertura superficial: Latossolo, Cambissolo, Neossolo, Gleissolo, ocorrendo também em algumas unidades o afloramento de rochas. A topografia é caracterizada por terrenos de declividade média (de 12 a 20\%, - predominante), a média/alta (20 a 30\% e $\geq 30 \%$ ). De acordo com Köppen (1948), o clima na área de estudo é classificado como mesotérmico subtropical úmido (Cfa). A temperatura média anual é $17-18{ }^{\circ} \mathrm{C}$, a precipitação varia entre $1.800-2.000 \mathrm{~mm}$ e a evapotranspiração anual é 900-1.000 mm (Caviglione et al., 2000). O uso da terra não é diversificado, em sua maioria é composto por floresta secundária $(53,9 \%)$, pastagem $(19,88 \%)$, e reflorestamento $(11,28 \%)$.

\subsection{Trabalho de campo}

O trabalho de campo consistiu na identificação dos impactos provocados pela localização e manutenção das estradas rurais. Procurou-se, por meio de registros fotográficos e inspeção em campo, 


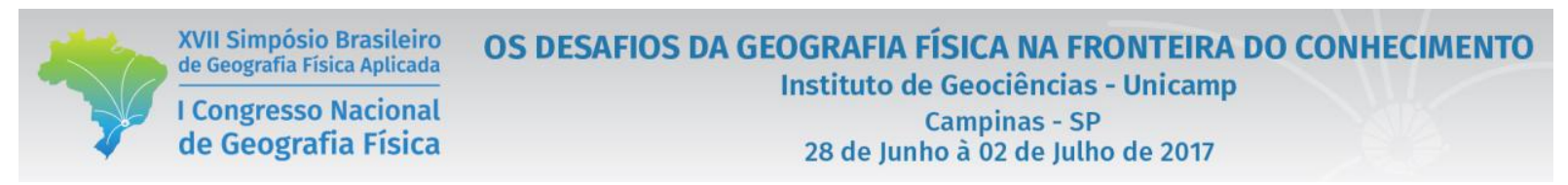

verificar os tipos de degradação das estradas de acordo com as unidades geomorfopedológicas onde elas estão construídas (ex. setores declivosos, zonas de saturação, áreas côncavas e outros).

Os locais de inspeção tiveram como objetivo envolver as unidades da bacia hidrográfica, que satisfaçam ao objetivo proposto da pesquisa, sendo estes locais de alta, média e baixa vertente, representando toda a área de estudo. Ao todo foram percorridos $130 \mathrm{~km}$ de estradas rurais, sendo estas estradas principais e caminhos internos. Para isso houve a utilização de alguns equipamentos, como: trena laser (DLE 50 Professional), trena métrica, suporte de madeira, clinômetro (CST), Sistema de Posicionamento Global-GPS de navegação, máquina fotográfica digital, prancheta e caderneta para anotação.

Os trabalhos de campo tiveram como objetivo verificar os problemas hidrogeomorfológicos existentes nas vias. Na avaliação das estradas, foram considerados os problemas, que são encontrados na plataforma de rolamento e áreas adjacentes, como buracos e ravinas, condições de drenagem, presença de dissipadores de energia, vegetação e outros.

\section{RESULTADOS E DICUSSÃO}

\subsection{Características das estradas nos níveis nacional, estadual, municipal e local}

Segundo o Departamento Nacional de Infraestrutura de Transporte-DNIT (2014), por tipo de superfície o Brasil possui $87 \%$ de vias não pavimentadas e aquelas que são planejadas somam apenas 129.262,00 (7,6\%) km (Tabela 1).

Tabela I- Malha viária existente nos níveis nacional, estadual, municipal e local.

\begin{tabular}{cccccc}
\hline Local & $\begin{array}{c}\text { Vias } \\
\text { pavimentadas } \\
(\mathbf{k m})\end{array}$ & $\begin{array}{c}\text { Vias } \\
\text { pavimentadas } \\
(\mathbf{\%})\end{array}$ & $\begin{array}{c}\text { Vias não } \\
\text { pavimentadas } \\
\mathbf{( k m )}\end{array}$ & $\begin{array}{c}\text { Vias não } \\
\text { pavimentadas } \\
(\boldsymbol{\%})\end{array}$ & $\begin{array}{c}\text { Total de } \\
\text { vias } \\
(\mathbf{k m})\end{array}$ \\
\hline Brasil & $202.988,10$ & 13 & $1.358 .913,70$ & 87 & $1.561 .901,8$ \\
Paraná & $19.343,3$ & 16,4 & $98.172,9$ & 83,6 & $117.516,2$ \\
Guarapuava & 160,10 & 15,1 & 896,28 & 84,9 & $1.056,38$ \\
$\begin{array}{c}\text { Bacia do Rio } \\
\text { Guabiroba }\end{array}$ & 0 & 0 & 130 & 100 & 130 \\
\hline
\end{tabular}

Fonte: Departamento Nacional de Infraestrutura de Transporte-DNIT (2014)

Departamento de Estrada e Rodagem-DER (2014).

Fonte: Elaborado pelas autoras (2017). 


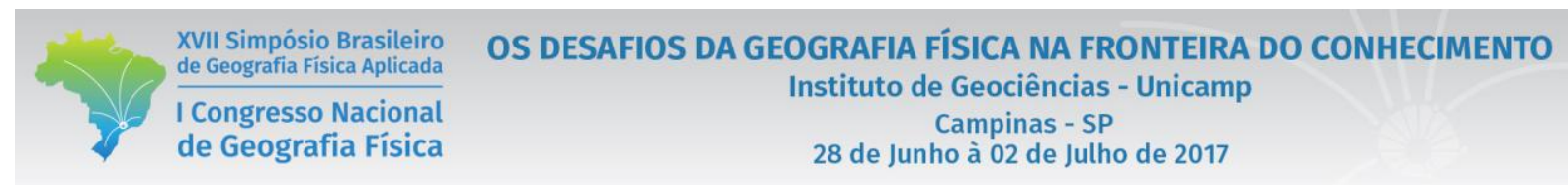

Em relação à rede rodoviária nacional não pavimentada por jurisdição 12.661,70 (0,9\%) km são de estradas Federais, 111.333,70 (8,2\%) km são Estaduais e a maioria sendo um total 1.234.918,30 $(90,9 \%) \mathrm{km}$ é Municipal (DNIT, 2014). Existe semelhança significativa de estradas sem pavimentação nos três níveis destacados (nacional, estadual e municipal) média de 85,1\%. Na bacia do Rio Guabiroba existem somente estradas sem pavimentação (Figura 2).

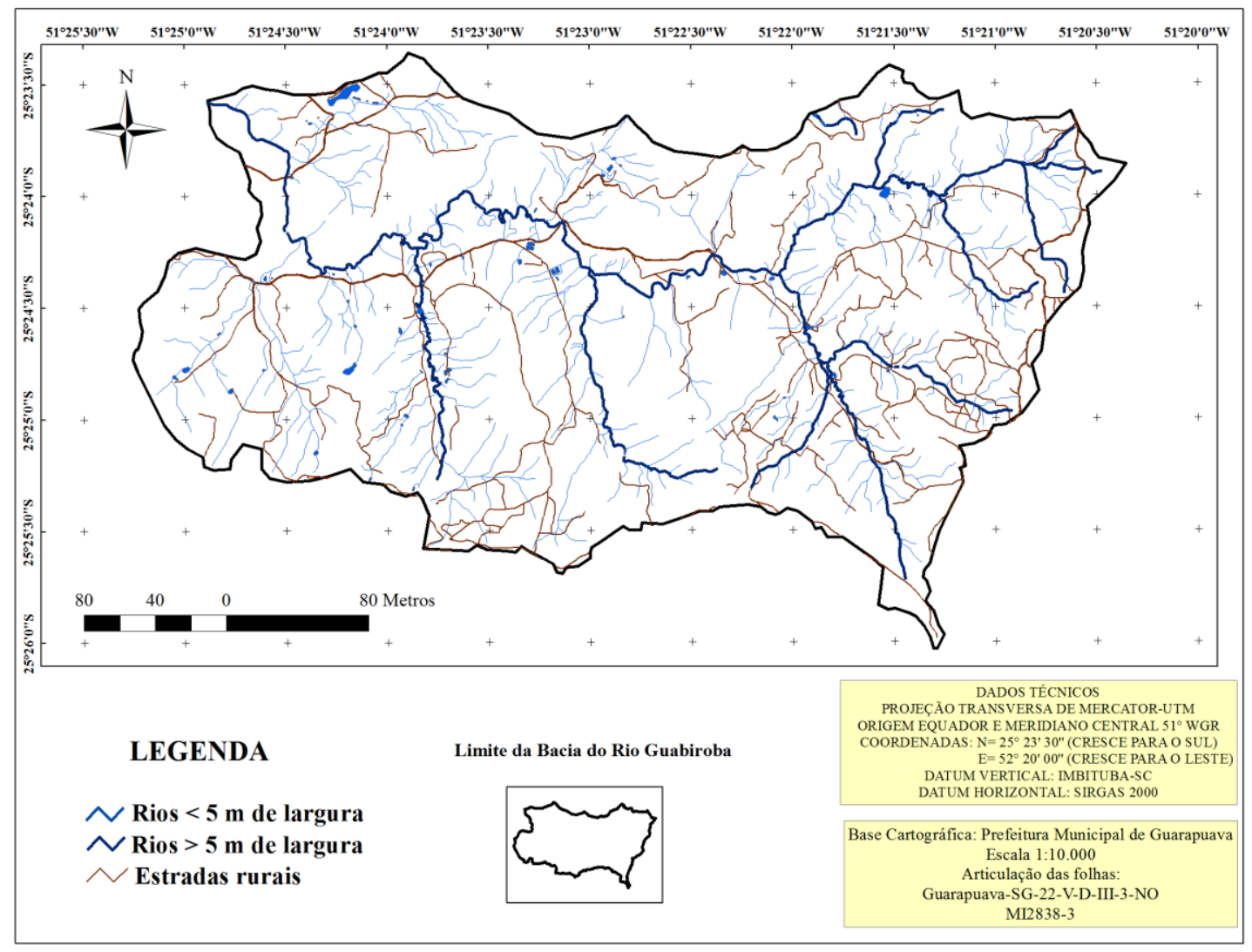

Figura 2- Rede viária e rede de drenagem da bacia do Rio Guabiroba

Fonte: Elabora pelas autoras (2017).

\subsection{Impactos gerados pela implantação e manutenção das estradas rurais}

Verificamos que uma das peculiaridades do sistema de estradas na área de estudo é que seu leito geralmente acompanha o fundo de vale (estradas principais), considerando que é mais viável a sua construção, pois sendo implantadas em tais condições utiliza-se a melhor localização e facilidades do terreno. Por outro lado, as estradas secundárias e caminhos internos são construídos em todos as unidades da bacia.

As condições em que as estradas não pavimentadas foram construídas na área de estudo, sendo incialmente implantas pelos colonizadores e, posteriormente, manuseadas pelos moradores locais, 
XVII Simpósio Brasileiro

de Geografia Fisica Aplicada

I Congresso Nacional

de Geografia Física
OS DESAFIOS DA GEOGRAFIA FÍSICA NA FRONTEIRA DO CONHECIMENTO

Instituto de Geociências - Unicamp

Campinas - SP

28 de Junho à 02 de Julho de 2017

ocasionaram problemas como rampas acentuadas de difícil trafegabilidade, encostas instáveis e de difícil manutenção, expondo, muitas vezes, perfis do solo susceptíveis à erosão (CUNHA, 2016). Como consequência, ocorrem estradas encaixadas na encosta, taludes expostos, pistas sem controle de drenagem superficial e subsuperficial, ausência de vegetação em áreas de entorno, cruzamentos de estradas e rios, potencializando a degradação tanto da estrada como do canal fluvial.

A localização destas estradas e a sua proximidade com os cursos d'água podem aumentar o transporte de sedimentos, pois se deve realizar nesses trechos técnicas que contribuam com a minimização dos problemas gerados pelas mesmas por meio principalmente do assoreamento. No caso dessas estradas, a maioria dos trechos avaliados possui cascalho agregado na plataforma, principalmente nas consideradas principais onde o tráfego é maior; já nas secundárias e caminhos internos, boa parte apresenta solo nu (Figura 3).
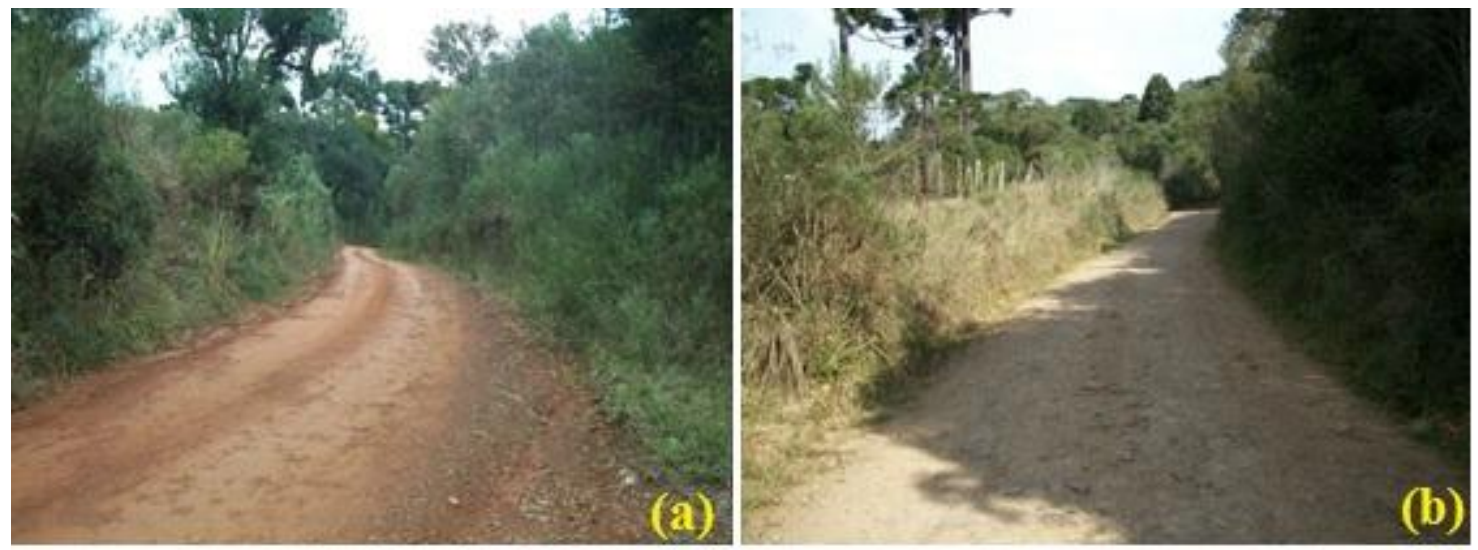

Figura 3- Características das estradas rurais da bacia do Rio Guabiroba. Em (a) estrada em solo nu, com presença de ravinas na margem direita, e em (b) estrada com cascalho na faixa de rolamento.

Fonte: Foto das autoras (2017).

Grande parte da região Centro-Sul do Paraná (ex. bacia do Rio Guabiroba), particularmente, são terras dissecadas ocupadas por agricultura familiar, florestas e reflorestamento. Nas terras dissecadas, as estradas, carreadores e caminhos são implantados em diferentes unidades geomorfopedológicas, e muitas vezes, não é considerada a aptidão do terreno (THOMAZ, 2009, CUNHA, 2011); assim, a conservação das estradas rurais em terras dissecadas é realizada com dificuldade.

Constatamos que muitos dos problemas nas estradas da bacia em questão ocorrem quando o sistema de drenagem não está adequado, ou seja, os mecanismos adotados na via, sendo esses caixas de contenção, lombadas e bigodes, não desempenham a função que é dissipar energia. A camada superficial das estradas de terra em geral sofre constantemente com a erosão, principalmente as estradas que estão localizadas num relevo significativamente acidentado, o que resulta na deformidade da pista de rolamento, 
surgindo ravinas, material solto para transporte e pista escorregadia. Em muitos casos a seção transversal é inadequada devido ao nivelamento da superfície de rolamento sem acréscimo de material, ou seja, parte do material da superfície é retirado, deixando a estrada encaixada no terreno, e em forma de calha, dificultando o escoamento de água para as laterais.

Observamos que na bacia do Rio Guabiroba muitos carreadores e caminhos internos das propriedades tornam-se intransitáveis devido ao forte ravinamento que se instala sobre o leito dessas vias de circulação. Segundo Oda et al., (2007) os maiores problemas em estradas rurais surgem em razão de seção transversal inadequada e ausência ou deficiência do sistema de drenagem. O tráfego e a ação das intempéries são outros fatores que contribuem para a deterioração das estradas.

De acordo com Kerniski e Cunha (2014) o tráfego médio das estradas na área de estudo é de 25 carros por dia (estradas principais), totalizando um fluxo médio de 750 carros mensais e 9.000 carros anuais variando de carros de passeio, motos, caminhões, e veículos escolares. Esses veículos são, sobretudo de moradores que trabalham na área urbana e também os de transporte escolar. Já a utilização das estradas para transporte da produção agrícola se intensifica em determinadas épocas do ano principalmente em períodos de plantio e colheita. A maioria das estradas são antigas, e foram construídas em solos argilosos, o que aumenta os problemas em épocas de chuva, como por exemplo, os atoleiros e a pista escorregadia (CUNHA, 2011; CUNHA e THOMAZ, 2015).

Com relação ao sistema de drenagem, é realizado por valas laterais, pois em alguns casos não possui dissipadores de energia com presença apenas de caixas de infiltração, sendo que muitas dessas caixas foram construídas de forma inadequada ou estão sem manutenção. A estrada considerada principal apresenta-se com revestimento de cascalho, com muito material grosseiro em alguns pontos; em várias partes do trecho encontramos pequenos buracos, e presença de ravinas. Os taludes em partes do trajeto foram encontrados dissecados, sem a presença de vegetação, podendo essa ausência ocasionar erosão, quando o volume de água for mais intenso.

No caso da área de estudo, isso foi evidenciado principalmente nos períodos de chuvas mais severas, em que as vias ficam intransitáveis devido aos atoleiros que se instalam. Segundo Cunha (2016) no ano de 2014, por exemplo, no mês de junho, houve 3 eventos pluviométricos excepcionais quando comparados aos outros meses do mesmo ano, sendo os seguintes eventos: (06/06/14 com 84,4 mm, 07/06/14 com total de 250,2 mm e 08/06/14 com 72,8 mm), somando assim, (407,4 mm) em somente três dias. 


\section{OS DESAFIOS DA GEOGRAFIA FÍSICA NA FRONTEIRA DO CONHECIMENTO \\ Instituto de Geociências - Unicamp \\ Campinas - SP \\ 28 de Junho à 02 de Julho de 2017}

\subsection{Medidas adotadas em manutenção de estradas rurais}

Alguns autores propõem medidas de conservação das estradas rurais: Baesso e Gonçalves (2003), Cunha (2011), Thomaz et al., (2013), são alguns exemplos. Entre essas medidas preventivas ou mitigadoras pode-se destacar: a drenagem superficial do leito das estradas, construção de sarjetas, bigodes, dissipadores de energia, implantação de caixas de infiltração, técnicas de vegetação. Estes são alguns exemplos das medidas que podem ser adotadas para melhora das condições das vias.

Baesso e Gonçalves (2003) destacam que é fundamental as boas condições de rolamento e aderência das estradas rurais, devendo garantir condições satisfatórias de tráfego, estando as condições de rolamento intimamente relacionados com a regularização da pista. As vias não pavimentadas necessitam de atenção principalmente pelos órgãos públicos devido ao planejamento correto da manutenção adequada, especialmente na drenagem. Macdonald et al., (2001) constataram que as estradas Virgin Islands (Porto Rico), sem pavimentação, geraram escoamento em precipitação acima de $6 \mathrm{~mm}$ e a produção de sedimento variou entre 10 a $15 \mathrm{~kg} / \mathrm{m}^{2} /$ ano. Esses autores confirmaram, ainda, que as estradas podem influenciar a resposta hidrológica dos canais fluviais, bem como no aumento de entrada de sedimento nos corpos hídricos.

As estradas da bacia do Guabiroba apresentam alguns problemas visíveis ao longo da pista de rolamento. A presença de trechos com declividade acentuada causa dificuldades no tráfego nos períodos chuvosos. As estradas apresentam no transcorrer de sua continuidade trechos com falta de manutenção das valas, o que ocasiona acúmulo de água na plataforma, gerando funcionamento inadequado dos dispositivos de drenagem superficial, Figura 4. 

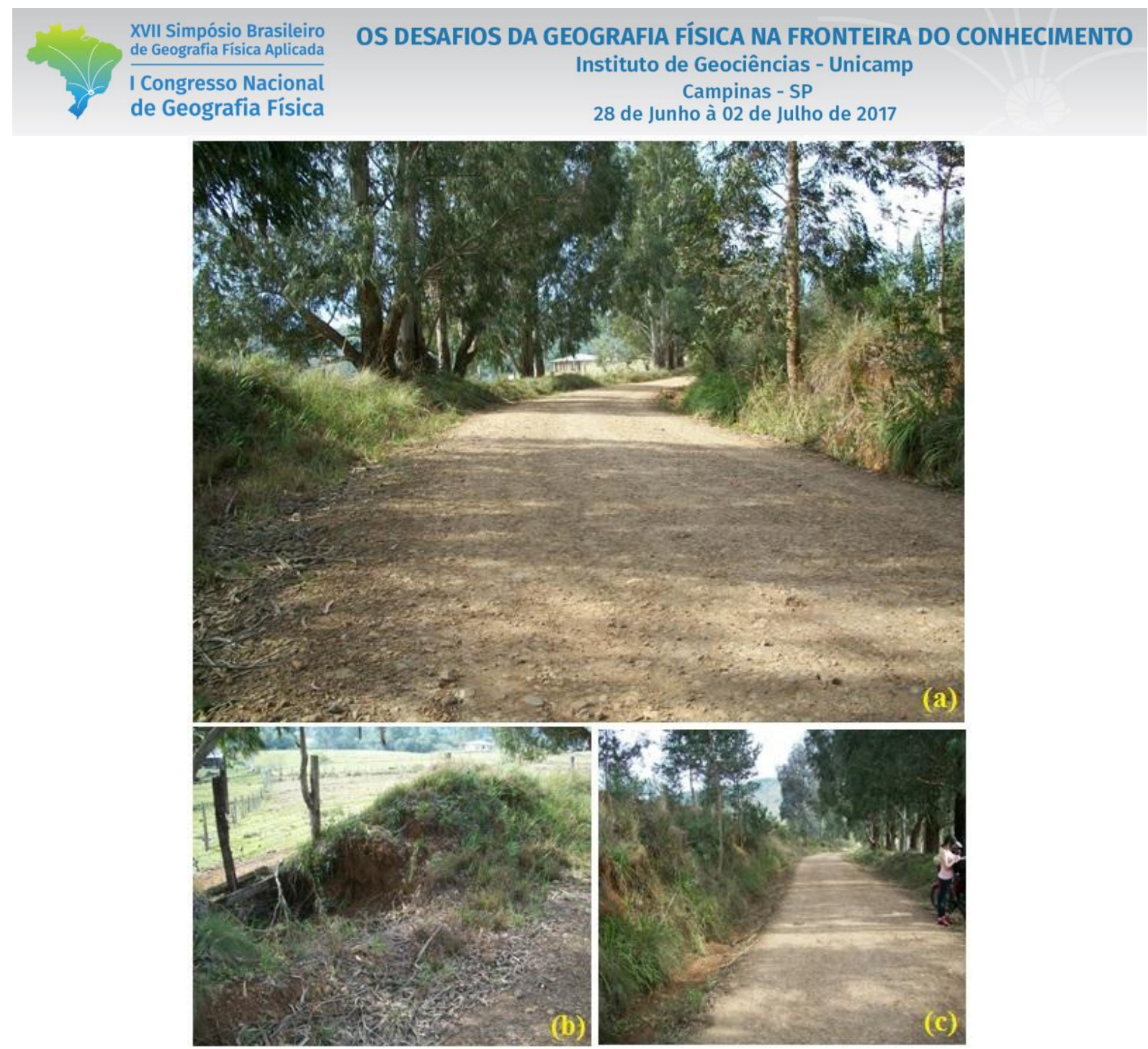

Figura 4- Problemas ocasionados pela falta de manutenção das estradas. Em (a) estrada sem sistema de drenagem lateral, em (b) ausência de manutenção no sistema de drenagem da estrada (caixa de infiltração), e em (c) vala na margem esquerda sem limpeza periódica.

Fonte: Foto das autoras (2017).

Como consequência o fluxo de água sobre pista de rolamento ao longo do tempo afeta as condições de suporte dos materiais que constituem seu subleito, fazendo com que a situação evolua para os defeitos mais severos, como atoleiros ou até trilhas de roda. A solução para este problema está na recomposição da drenagem superficial nas sarjetas (BAESSO e GONÇALVES, 2003). Os autores ressaltam ainda, que além dos problemas elencados, estima-se que a má gestão quanto à manutenção de estradas na América Latina e no Caribe, por exemplo, ocasiona um aumento desnecessário nos custos de operação de veículos, que pode equivaler entre 0,5 e 1\% do Produto Interno Bruto (PIB) (BAESSO e GONÇALVES, 2003).

Sendo assim notamos que existem vários problemas nas estradas rurais na área de estudo, e para que estes problemas sejam amenizados é de fundamental importância que sejam realizados trabalhos de 
manutenção periódica bem como acompanhamento do estado de conservação dessas vias, levando sempre em consideração o tipo de terreno e a localização da mesma.

\section{CONCLUSÕES}

A localização das estradas e a sua proximidade com os cursos d'água podem aumentar o transporte de sedimentos, quando não tratados adequadamente, ou diminuí-los, desde que sejam realizadas técnicas que contribuam com a minimização dos problemas gerados pelas mesmas, principalmente o assoreamento.

Verificamos nas estradas avaliadas que há dispositivos de drenagem, mas muitos desses estão sem manutenção ou estão inadequados, ou seja, foram construídos de forma irregular e por isso não têm a eficácia desejada, não contribuindo para a desaceleração do escoamento superficial.

As estradas rurais da bacia do Rio Guabiroba foram implantadas inicialmente pelos colonizadores sem técnicas apropriada, por ter sido orientada pela estrutura fundiária e pelas facilidades do terreno. Portando, a manutenção frequente e adequada é importante para reduzir os custos de reconstrução em longo prazo, particularmente no que se refere ao revestimento primário e as estruturas de drenagem, e quanto maior for o nível de agregação de informações em relação às condições das estradas rurais, mais elevado é o nível de decisão na manutenção destas vias.

\section{AGRADECIMENTOS}

À Coordenação de Aperfeiçoamento de Pessoal de Nível Superior (CAPES) por ter concedido bolsa de estudos.

\section{REFERÊNCIAS}

BAESSO, D. P.; GONÇALVES, F. L. R. Estradas não pavimentadas: técnicas adequadas de manutenção. Florianópolis: DER, 2003. 204 p.

DER- Departamento de Estradas de Rodagem. Curitiba-PR, 2014.

DNIT- Departamento Nacional de Infraestrutura de Transportes, 2014.

CAVIGLIONE, J. H.; KIIHL, L. R. B.; PH, C.; OLIVEIRA, D. Cartas climáticas do Paraná. IAPAR-Instituto Agronômico do Paraná, Londrina, 2000.

CHAPPELL, N. A. Soil pipe distribution and hydrological functioning within the humid tropics: a synthesis. Lancaster Environment Centre, Lancaster University, Lancaster LA1 4YQ, UK. Hydrol. Process. v. 24, p. 1567-1581, 2010. 
CHENG, B. L. V.; ZHAN, Y. S. U.; CAO, S. Constructing China's roads as works of art: a case study of 'esthetic greenway' construction in the Shennongjia region of China. Land Degradation and Development 26 (4), 324-33, 2015.

CUNHA, M. C. Avaliação da eficácia das caixas de contenção de sedimento em estradas rurais não pavimentadas na Bacia o Rio Das Pedras, Guarapuava-Pr, Guarapuava, Universidade Estadual do Centro Oeste, 2011.

CUNHA, M. C. Processos hidrológicos subsuperficiais influenciados por cortes de estradas não pavimentadas. (Tese Doutorado em Geografia). Universidade Federal do Paraná, Setor de Ciências da Terra, Programa de PósGraduação em Geografia. Curitiba, 134p., 2016.

CUNHA, M. C.; THOMAZ, E. L. É possível reduzir a turbidez da água em bacia rural por Meio de implantação de caixas de infiltração? Revista Brasileira de Geomorfologia, São Paulo 16 (4), 657-667, 2015.

CUNHA, M. C.; THOMAZ, E. L.; VESTENA, L. R. Medidas de controle de erosão em estradas rurais na bacia do rio das Pedras, Guarapuava-PR. Revista Sociedade \& Natureza-Uberlândia-MG, n $^{\circ} 25$ (1): 107-118, jan/abr/2013.

FAIZ, A.; FAIZ, A.; WANG, W.; BENNETT, C. Sustainable rural roads for livelihoods and livability. Procedia - Social and Behavioral Sciences v. 53, p. 1-8. DOI: 10.1016/j.sbspro.2012.09.854, 2012.

KERNISKI, M. M.; CUNHA, M. C. Importância das estradas não pavimentadas para a localidade da bacia do Rio Guabiroba, Guarapuava-PR. VII Congresso Brasileiro de Geógrafos. Vitória-ES, ISBN 978-85-98539-04-1, 2014.

KÖPPEN, W. Climatologia. México, Fundo de Cultura Econômica, 1948.

LUCE, C. H.; WEPLE, B. C. Introduction to special issue on hydrologic and geomorphic of forest roads. Earth Surface Processes and Landforms, v. 26, p. 111-113, 2001.

MACDONALD, L. H.; SAMPSON, R. W.; ANDERSON, D. M. Runoff and road erosion at the plot and road segment scales, St. John, US Virgin Islands. Earth Surface Processes and Landforms, v. 26, p.251 - $272,2001$.

MINEROPAR. Atlas Geológico do Estado do Paraná. Curitiba, MINEROPAR Serviço Geológico do Paraná, 2001.

ODA, S.; FERNANDES JÚNIOR, J. F.; SÓRIA, M. H. A. Implantação, localização e manutenção de estradas. Departamento de transporte-EESC-USP, Universidade de São Paulo, 2007.

THOMAZ, E. L. Processos Geomorfológicos e balanço de sedimentos em bacia de drenagem. In: Leandro Redin Vestena, Paulo Nobokuni, Márcia da Silva, Edivaldo Lopes Thomaz. Saberes Geográficos: Teorias e Aplicações. Guarapuava: Unicentro, 2009, 298p.

THOMAZ, E. L.; MELQUIADES, F. L. Discriminação de marcadores de proveniência de sedimento em bacia rural por meio de EDXRF. Revista Brasileira de Geomorfologia, v. 10, p. 95-102, 2009.

THOMAZ, E. L.; PERETTO, G. T. Hydrogeomorphic connectivity on roads crossing in rural headwaters and its effect on stream dynamics. Science of the Total Environment 550 (1), 547-555, 2016.

THOMAZ, E. L.; VESTENA, L. R.; RAMOS-SCHARRÓN, C. E. The effects of unpaved roads on suspended sediment concentration at varying spatial scales - a case study from Southern Brazil. WEJ (Hertford), v. 28 , p. 547-555, 2014.

WEMPLE, B. C. Assessing the Effects of Unpaved Roads on Lake Champlain Water Quality. Lake Champlain Basin Program. Technical report no. 74, 2013. 